REGARDS

SUR L'ECONOMIE ALLEMAND

BULLETIN ECONOMIQUE DU CRRAC
Regards sur l'économie allemande

Bulletin économique du CIRAC

104 | 2012

Varia

\title{
Du bon usage du « modèle allemand »
}

\author{
René Lasserre
}

\section{OpenEdition}

Journals

Édition électronique

URL : http://journals.openedition.org/rea/4381

DOI : 10.4000/rea.4381

ISBN : 978-2-8218-1286-4

ISSN : 1965-0787

Éditeur

CIRAC

Édition imprimée

Date de publication : 13 avril 2012

Pagination : 1-2

ISSN : 1156-8992

Référence électronique

René Lasserre, «Du bon usage du « modèle allemand » », Regards sur l'économie allemande [En ligne], 104 | avril 2012, mis en ligne le 17 avril 2012, consulté le 22 septembre 2020. URL : http:// journals.openedition.org/rea/4381 ; DOI : https://doi.org/10.4000/rea.4381 


\section{Du bon usage du " modèle allemand"}

Alors que les économies de l'Europe du Sud, confrontées aux difficultés de refinancement de leur dette souveraine, doivent adopter des mesures d'économies budgétaires drastiques qui risquent de les enfoncer dans la récession et que la France, également contrainte à l'assainissement de ses comptes publics, est aux prises avec une crise de compétitivité qui hypothèque durablement son redressement, l'Allemagne sort renforcée de la crise et affiche, sur tous les fronts, une santé économique resplendissante. Sous l'effet d'une dynamique de croissance solide qui continue de s'appuyer sur des excédents extérieurs record et sur une demande interne soutenue, le pays a réussi à réduire le chômage à son plus bas niveau depuis vingt ans et est en passe de rétablir l'équilibre de ses comptes publics. En cela, et dans le contexte de la crise profonde qui vient d'affecter l'économie mondiale, l'Allemagne fait figure, au sein de l'Union européenne, de modèle de référence auquel ses partenaires, et au premier rang desquels le principal d'entre eux, la France, sont appelés à évaluer objectivement leurs performances et à reconsidérer la validité de leurs choix économiques et sociaux.

En période électorale, à l'approche d'une échéance politique majeure, on comprend ce que cela peut avoir d'inconfortable et d'ambivalent pour les responsables et les formations politiques et aussi ce que cela peut susciter de perplexité dans l'opinion. Et l'on voit bien en l'occurrence, qu' à défaut de vouloir s'engager dans ce benchmark des politiques publiques européennes qu'appelle pourtant la réalité politique, économique et sociale de l'Europe d'aujourd'hui, le débat politique national reste englué dans une démarche purement hexagonale qui relève d'un déni d'Europe. Nos responsables politiques et nombre de leaders d'opinion se livrent à de dérisoires entrechats : tantôt ils pratiquent l'esquive sous la forme d'une large conspiration du silence, tantôt ils cèdent à la désinformation caractérisée, sport intellectuel national par lequel nos élites soumettent les réalités étrangères au prisme déformant de leurs préjugés idéologiques hexagonaux. Ainsi en va-t-il d'une pièce maîtresse de la politique allemande de réforme : celle du marché du travail instaurée par les lois Hartz. Au regard d'un large éventail de la recherche en sciences sociales, de la presse et de l'opinion françaises, elle aurait instauré une précarisation de l'emploi à grande échelle et une montée alarmante de la pauvreté en Allemagne ! L'une et l'autre sont certes d'indéniables réalités allemandes ; il convient cependant d'évaluer ces réalités à leurs justes proportions et à leurs causes effectives, comme le font les deux contributions sur la flexibilité de l'emploi et l'accroissement des inégalités de revenu que nous publions dans le présent numéro.

Tout aussi ambivalent, voire contreproductif dans le débat public, est à l'inverse l'invocation récurrente du " modèle allemand " dans l'action gouvernementale. Une fois de plus, on a prétendu s'en inspirer pour promouvoir dans l'urgence une réforme importante des prélèvements sociaux à laquelle l'opinion a été mal préparée. Mais encore fallait-il que la référence à l'expérience allemande soit convaincante et appropriée. Tel ne fut cependant pas le cas avec la mise en place de la "TVA sociale " dont l'objectif salutaire est

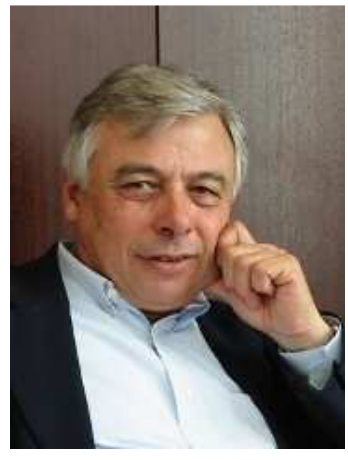

Prof. René Lasserre, Directeur du CIRAC 
certes de diminuer très sensiblement et à grande échelle les charges sociales qui pèsent sur les entreprises. Mais comme le montre l'intéressante étude comparative de la fiscalité indirecte de Christophe Strassel dans ce numéro, l'Allemagne ne l'a que ponctuellement et très modestement pratiquée lors du relèvement de la TVA en 2007. C'est en fait un choix radicalement différent qu'elle a opéré en donnant largement la priorité à un allègement substantiel de la fiscalité directe pesant sur l'entreprise et en réaménageant parallèlement le financement de la protection sociale, de sorte qu'en matière de TVA sociale, pas plus d'ailleurs qu'en matière de CSG, notre voisin ne dispose d'expérience réellement éprouvée.

A défaut d'être transposable globalement ou dans tel ou tel de ses différents registres, la politique de réformes menée en Allemagne au cours des quinze dernières années n'en constitue pas moins, par sa cohérence et sa réussite, une référence incontournable pour ses partenaires européens dans la définition de leurs politiques de modernisation et d'adaptation structurelles aux données nouvelles de la globalisation. Le succès de l'expérience allemande de la seconde moitié des années 2000 procède d'une action réformatrice de longue haleine et, au plein sens du terme, délibérée. Celle-ci est l'œuvre construite des acteurs socio-économiques et politiques qui, pas à pas, et au prix d'ajustements successifs, sont parvenus à conjuguer leurs efforts autour d'un projet global cohérent ayant pour objectif partagé de restaurer la compétitivité internationale de leur économie. Combinant successivement modération salariale et flexibilité, réforme du marché du travail et allègement des coûts sociaux, consolidation des finances publiques, baisse de la fiscalité des entreprises et promotion de l'innovation, cette stratégie allemande de compétitivité globale a procédé d'une démarche conséquente et fait la preuve de son efficacité. En restaurant en profondeur la profitabilité de l'entreprise tout en rétablissant la capacité d'intervention structurelle de l'Etat, elle a permis au pays de résister à la crise et d'en sortir avec une vitalité renforcée.

En cela, la politique économique de l'Allemagne constitue sans aucun doute un cas d'école qui s'appuie sur une méthode et des préceptes éprouvés dont ses partenaires peuvent s'inspirer, à charge pour eux de les mettre en $œ u v r e$ en fonction de leurs capacités propres. Au premier rang de ces préceptes figurent la volonté du corps social de faire prévaloir et de préserver la profitabilité de l'entreprise, la capacité des pouvoirs publics à assurer à cette dernière un environnement compétitif, tant au plan des conditions générales d'activité qu'à celui de la qualification et de la valorisation du facteur humain et de l'équilibre social.

Vaste programme pour une France où l'entreprise reste mal aimée, où les partenaires sociaux ont perdu une large part de leur légitimité, où la dépense publique et sociale tient lieu de vecteur principal de la croissance, où l'initiative et la création de richesse sont étouffées par un Etat omniprésent lequel se définit d'abord comme le garant des acquis sociaux plutôt que de se faire le promoteur efficace du changement.

René Lasserre, le 10 avril 2012 